\title{
A new wing skeleton of Forfexopterus (Pterosauria: Ctenochasmatidae) from the Early Cretaceous Jehol Biota reveals a developmental variation
}

\author{
Chang-Fu Zhou, Jiahao Wang, and Ziheng Zhu \\ College of Earth Science and Engineering, Shandong University of Science and Technology, Qingdao, \\ Shandong Province, China
}

Correspondence: Chang-Fu Zhou (zhoucf528@163.com)

Received: 8 January 2020 - Revised: 22 August 2020 - Accepted: 27 August 2020 - Published: 9 October 2020

\begin{abstract}
In the Jehol Biota, the filter-feeding ctenochasmatid pterosaurs flourished with a high biodiversity. Here, we report a new wing skeleton of the ctenochasmatid Forfexopterus from the Early Cretaceous Jiufotang Formation in Jianchang, western Liaoning, China. The specimen exhibits the sole autapomorphy, the first wing phalanx shorter than the second and longer than the third. Interestingly, it exhibits a skeletal maturity with co-ossified elements, but it is only about $75 \%$ the size of the immature holotype. This discrepancy reveals developmental variation of Forfexopterus, but its relationship with sexual dimorphism needs to be certain by more available material.
\end{abstract}

\section{Introduction}

In the Jehol Biota, the filter-feeding ctenochasmatid pterosaurs flourished with a high diversity. They are well known for their slender and long teeth for filtering tiny food in the water. Most ctenochasmatids are known from the Yixian Formation (ca. 126-122 Ma; Chang et al., 2009, 2017), such as Eosipterus, Feilongus, Beipiaopterus, Elanodactylus, Gegepterus, Pterofiltrus, Cathayopterus, and Gladocephaloideus. Recently, Feilongus and Gladocephaloideus were also reported from the overlying Jiufotang Formation (e.g., Wang et al., 2005; Lü et al., 2016). In addition, two taxa - Moganopterus and Forfexopterus - are only known from the Jiufotang Formation in Lamadong Town, Jianchang County, western Liaoning Province (Lü et al., 2012; Jiang et al., 2016). In this area, the lacustrine sediments are recognized as the Jiufotang Formation based on biostratigraphic data (e.g., Pan et al., 2015; Wu et al., 2018) and isotopic dating (120 $\pm 1.0 \mathrm{Ma}$; Jiang et al., 2016).

Here, we report a new ctenochasmatid specimen from the same area based on a forelimb. It is proportionally comparable with Forfexopterus jeholensis (HM V20, Hami Museum, Hami, China; the type and sole specimen) in which the first wing phalanx is shorter than the second phalanx and longer than the third phalanx (Jiang et al., 2016). This new specimen has a smaller wing span, about $75 \%$ of that of HM V20 (the wing span is $237 \mathrm{~cm}$, calculated from Jiang et al., 2016). Interestingly, it exhibits osteological maturity, in contrast to the immature HM V20, revealing developmental variation of Forfexopterus, as in other known pterosaurs (e.g., Rhamphorhynchus, Pteranodon).

\section{Material and methods}

The specimen (SDUST-V1003, Shandong University of Science and Technology, Qingdao, China; Figs. 1,2) is preserved on a single slab. As in other pterosaurs of the Jehol Biota, it is flattened. The slab is a block of lacustrine sediments constituted of gray-grayish white shales, which was discovered from the Early Cretaceous Jiufotang Formation of the Xiaoyaogou site, about $3.5 \mathrm{~km}$ southwest to the Xiaotaizi site. Xiaotaizi is the type locality of Forfexopterus jeholensis, in Lamadong Town, Jianchang County, western Liaoning Province. The bones are well exposed after preparation. The right scapulocoracoid and the forelimb are in articulation. Moreover, three Jinanichthys-like fish fossils and some Galba-like shells are associated with the pterosaur fossil. 
The fossil was damaged during excavation at the distal third of the ulna and the radius, the syncarpals, and the proximal third of the pteroid. Distal phalanges and unguals of the manual digits II-III are missing. The wing metacarpal is broken into three parts before the fossilization.

\section{Description}

The specimen (SDUST-V1003; Figs. 1, 2) represents a mature individual, characterized by ontogenetic features such as the co-ossified scapulocoracoid, the well-ossified epiphysis of the humerus, two syncarpals, and the extensor tendon process fused to the first wing phalanx (Bennett, 1993, 2001). SDUST-V1003 is about $178 \mathrm{~cm}$ in wing span, which was estimated by doubling the total length of the right forelimb (including the humerus, the ulna, the metacarpus, and four wing phalanges). In contrast, the type specimen of $F$. jeholensis (HM V20) is a subadult with a larger wing span of about $237 \mathrm{~cm}$ (calculated from Jiang et al. 2016).

The scapulocoracoid is co-ossified and " $\mathrm{L}$ "-shaped. It is well exposed in posterior view but partially overlapped by the second wing phalanx (Fig. 1). Therefore, the length of the scapular portion is uncertain but likely no shorter than the coracoid portion $(68 \mathrm{~mm})$. The glenoid fossa is saddleshaped (Fig. 2a). The scapular portion appears narrower than the coracoid portion. The scapular portion extends straightly above the glenoid fossa at the proximal third, and its distal shaft curves medially, forming an angle of $30^{\circ}$ with its proximal third. Under the fossa, the coracoid shaft extends medially. A ventral crest, referred to as the coracoid flange by Jiang et al. (2016), is weakly developed along the proximal half of the coracoid shaft, as in the type specimen of $F$. jeholensis (HM V20) and other ctenochasmatids (e.g., Beipiaopterus, Gegepterus, and Elanodactylus; Lü, 2003; Wang et al., 2007; Andres and Ji, 2008; Zhou, 2010). A similar structure is also known but highly varied in azhdarchoids (e.g., Liu et al., 2015). More medially, the coracoid expands anteroposteriorly and forms a concave facet at its distal end for the articulation with the sternum.

The humerus is exposed ventrally, with a length of $103 \mathrm{~mm}$. Proximally, it is positioned against the scapulocoracoid, but the humeral head is displaced from the glenoid fossa. Distally, the humerus is preserved in articulation with the ulna and the radius (Fig. 2b). Proximally, the humerus bears a well-developed deltopectoral crest and a posterior tubercle. As in the holotype, the deltopectoral crest is positioned at the proximal fourth of the humerus. It is plate-like and extends anteriorly but slightly curves ventrally at its distal end. A pneumatic foraman was reported at the base of the left deltopectoral in the holotype of $F$. jeholensis but illustrated on the base of the posterodorsal surface of the posterior tubercle (Jiang et al., 2016, fig. 3). In SDUST-V1003, this condition is uncertain, due to the posterior tubercle being exposed ventrally and slightly anteriorly. This exposure results in the tubercle positioned well beyond the shaft, as a taphonomic artifact. The posterior tubercle is roughly parallel with the humeral shaft in ctenochasmatoids (e.g., Elanodactylus, Forfexopterus; Andres and Ji, 2008; Jiang et al., 2016). The humeral shaft is nearly straight. Its minimum diameter is $11 \mathrm{~mm}$ immediately distal to the deltopectoral crest. The distal end of the humerus is expanded and well ossified (Fig. 2b). The medial condyle is exposed and highlypositioned at the distal end of the humerus. The intercondyle sulcus is partially exposed, but the lateral condyle is obscured by the overlapping radius and the ulna.

The ulna and the radius are very elongate to 152.2 and $149.2 \mathrm{~mm}$ respectively. The ulna is about $148 \%$ the length of the humerus, proportionally less than the $163 \%$ in the holotype of $F$. jeholensis (Jiang et al., 2016) but proportionally longer than in other archaeopterodactyloids of the Jehol Biota (e.g., 102\%-116\% in Elanodactylus, Andres and Ji, 2008; $110 \%$ in Beipiaopterus, Lü, 2003; $127.6 \%$ in Eosipterus, Lü et al., 2006; $130 \%$ in Gladocephaloideus, Lü et al., 2016). The ulna is more robust than the radius and partially overlapped the latter, as in the holotype of $F$. jeholensis (Jiang et al., 2016).

The carpus is damaged. It is preserved in articulation with the ulna and the radius proximally and the wing metacarpal distally. The proximal and distal carpals are co-ossified as syncarpals respectively. The preaxial carpal and sesamoid A can be identified together with the pteroid. However, the damage on the specimen hinders further observation.

The pteroid is damaged on its proximal third, which can be inferred from its impression. The pteroid is slender, rodlike and slightly curved proximally. It is $72.2 \mathrm{~mm}$ long, about $47.3 \%$ of the ulna, comparable to F. jeholensis (46.7\%, Jiang et al., 2016).

Metacarpals I-III are slender, relative to those in the holotype of $F$. jeholensis (Jiang et al., 2016, fig. 3). They are distally expanded and align together with the wing metacarpal. Proximally, the three metacarpals are separated, broken, and obscured by fragments of the wing metacarpal. They possibly had a contact with the distal syncarpal in life. The wing metacarpal is broken into three parts. Its proximal part is still in articulation with the distal syncarpal. This segment is about $26 \mathrm{~mm}$ long. Distally, it is displaced from the distal segment. The distal segment represents the main part of the wing metacarpal with a length of $78 \mathrm{~mm}$. The segment is broken proximally, showing a large medullary cavity. The bony wall is about $1 \mathrm{~mm}$ thick and has a smooth internal surface. Distally, the segment is articulated with the first wing phalanx. A third segment is the sidewall and possibly matches the broken side of the distal segment. The wing metacarpal is estimated as $110 \mathrm{~mm}$ in length based on the total length of these parts.

The manual digits I-III are partially preserved with their proximal phalanges. In manual digit I, the proximal phalanx is slender and rod-like with a length of $18 \mathrm{~mm}$. The ungual is preserved on its ventral half. The ungual shows a 


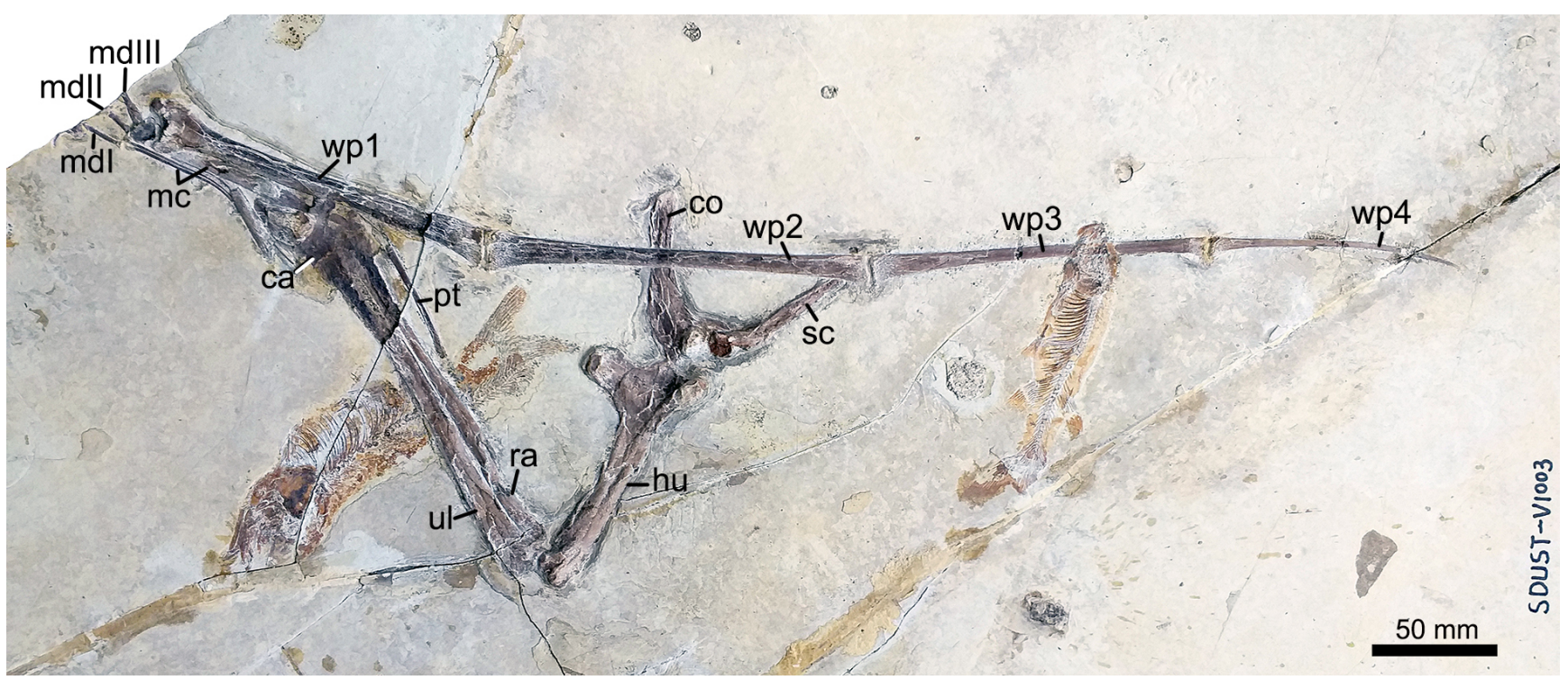

Figure 1. New wing skeleton of Forfexopterus (SDUST-V1003) from Jiufotang Formation of Early Cretaceous Jehol Biota in Jianchang, western Liaoning, northeastern China. Abbreviations: ca, carpus; co, coracoid portion; hu, humerus; mc, metacarpals I-IV; mdI-III, manual digits I-III; pt, pteroid; ra, radius; sc, scapular portion; ul, ulna; wp1-4, wing phalanges 1-4.
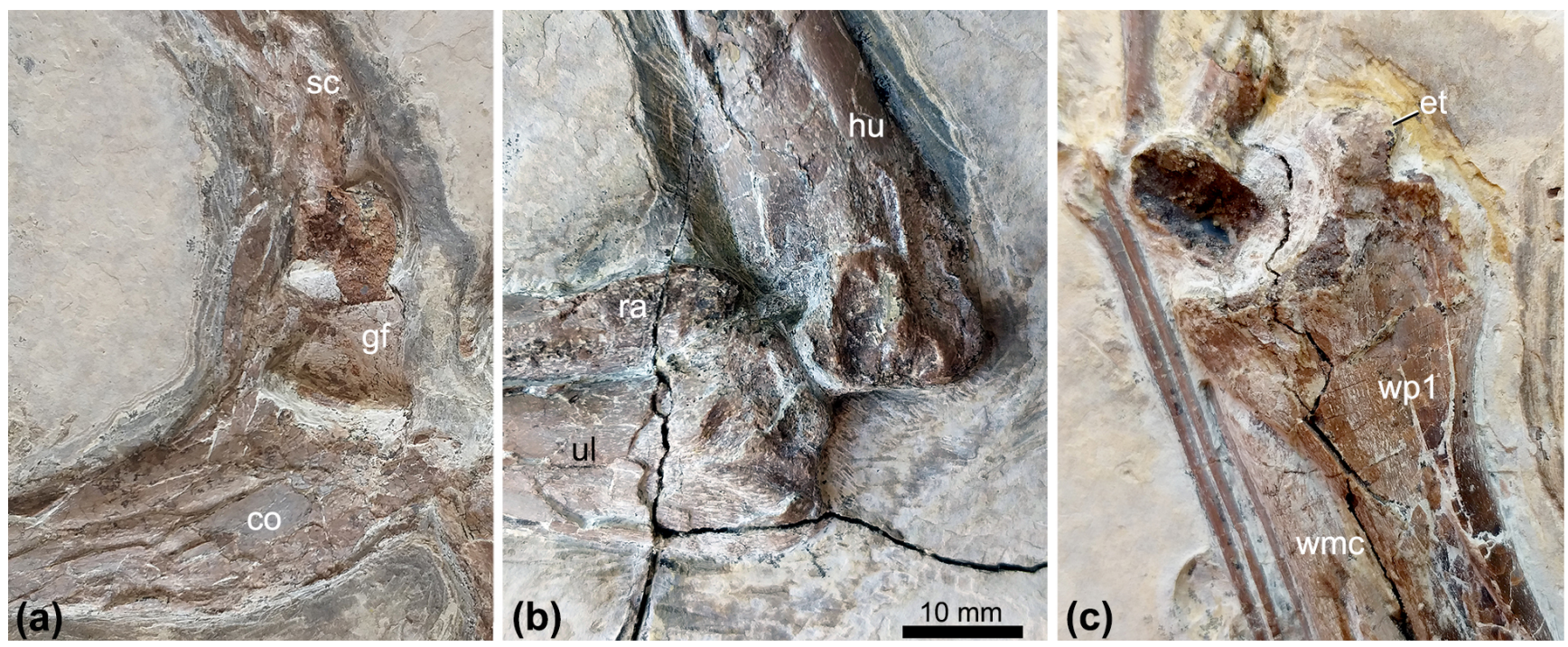

Figure 2. Enlarged images of the new wing skeleton of Forfexopterus (SDUST-V1003) from Jiufotang Formation of Early Cretaceous Jehol Biota in Jianchang, western Liaoning, northeastern China. (a) Glenoid fossa of the co-ossified scapulocoracoid; (b) elbow joint between the well-ossified humerus and ulna and radius; (c) extensor tendon process fused with the first wing phalanx. Abbreviations: co, coracoid portion; et, extensor tendon process; gf, glenoid fossa; hu, humerus; ra, radius; sc, scapular portion; ul, ulna; wmc, wing metacarpal IV; wp1, the first wing phalanx.

strong curvature and a large basal tubercle. In manual digit II, the proximal phalanx is relatively stout and has a length of $12 \mathrm{~mm}$. In manual digit III, the proximal phalanx is more robust than other proximal phalanges. It is distinctly longer than the proximal phalanx of the manual digit II, but its total length is uncertain.

In contrast, the wing phalanges are well preserved in articulation and exposed in dorsal view. They are straight and elongate, except for the fourth wing phalanx being slightly curved. The second wing phalanx is the longest $(153.5 \mathrm{~mm})$, the first wing phalanx $(147.6 \mathrm{~mm})$ is longer than the third wing phalanx $(131.9 \mathrm{~mm})$, and the fourth wing phalanx is the shortest $(98.7 \mathrm{~mm})$. The proportions of wing phalanges are comparable to those of $F$. jeholensis, in which the first wing phalanx is shorter than the second but longer than the third (Jiang et al., 2016; Table 1). Proximally, the first wing pha- 


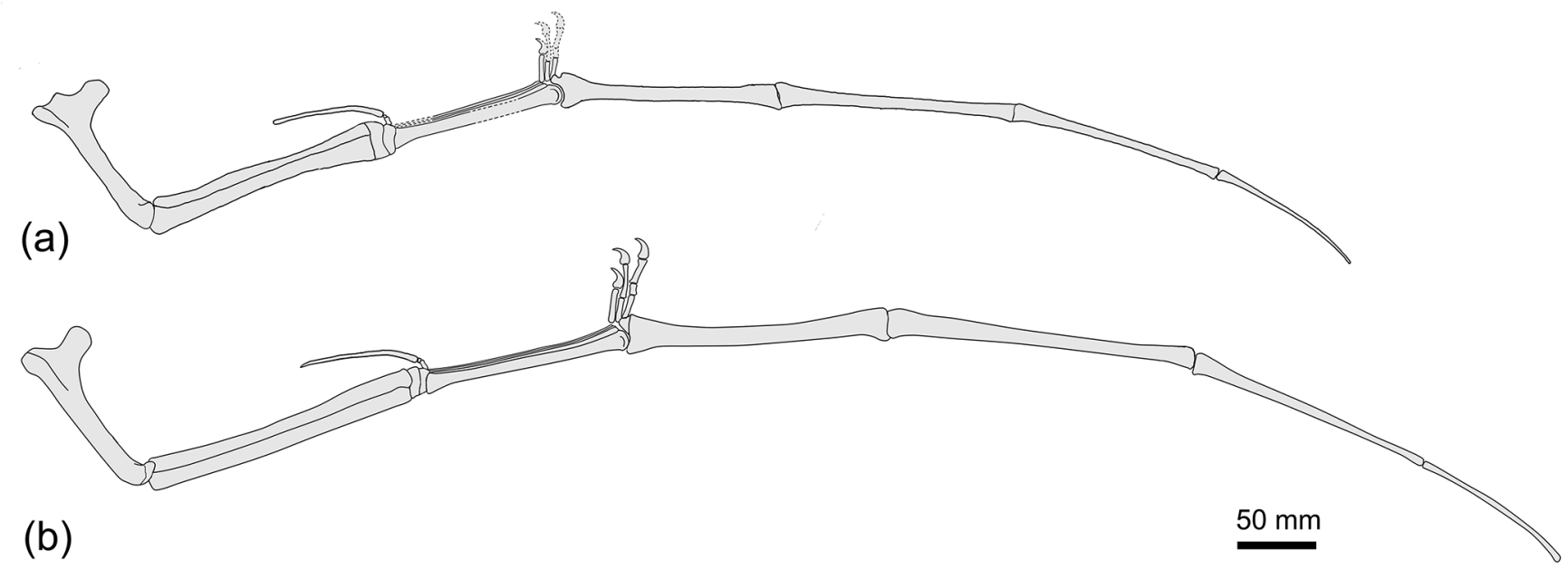

Figure 3. Disparity of Forfexopterus in wing size. (a) SDUST-V1003 (adult); (b) the holotype HM V20 (subadult; reconstructed from Jiang et al., 2016).

Table 1. Measurements and ratios of the wing skeleton (SDUSTV1003) and holotype (HM V20) of Forfexopterus.

\begin{tabular}{lrrr}
\hline Element & $\begin{array}{r}\text { SDUST-V1006 } \\
(\mathrm{mm})\end{array}$ & $\begin{array}{r}\text { HMV20 } \\
(\mathrm{mm})\end{array}$ & $\begin{array}{r}\text { Ratio } \\
(\%)\end{array}$ \\
\hline Scapular portion & $>68$ & 80 & $\mathrm{NA}$ \\
Coracoid portion & 68 & 81.4 & 83.5 \\
Humerus & 103 & 118 & 87.3 \\
Radius/ulna & $149.2 / 152.2$ & 192.2 & $77.6 / 79.2$ \\
Metacarpal IV & $110^{*}$ & 146.8 & $74.9^{*}$ \\
Pteroid & 72.2 & 89.7 & 80.5 \\
First wing phalanx & 147.6 & 192.8 & 76.6 \\
Second wing phalanx & 153.5 & 213.1 & 72.0 \\
Third wing phalanx & 131.9 & $188.8^{*}$ & $69.9^{*}$ \\
Fourth wing phalanx & 98.7 & 134.3 & 73.5 \\
\hline
\end{tabular}

* Estimated value; > preserved value. Data of HM V20 from Jiang et al. (2016). NA - not available.

lanx and the extensor tendon process are fully fused (Fig. 2c), indicative of maturity in pterosaurs.

\section{Discussion}

As mentioned in the description, the new specimen (SDUSTV1003) exhibits several features for assigning its affinity. For example, the metacarpus is elongated, which is a typical feature of the Pterodactyloidea (e.g., Unwin, 2003; Kellner, 2003; Andres et al., 2014). Furthermore, SDUST-V1003 can be assigned to the Archaeopterodactyloidea by the unwarped deltopectoral crest, subequal metacarpals, and the general proportions of the wing phalanges (e.g., Unwin, 2003; Kellner, 2003). In the Jehol Biota, the archaeopterodactyloids flourished with 11 named taxa, which are assigned to the clade Ctenochasmatidae (e.g., Andres et al., 2014; Zhou et al., 2017). Among the Jehol archaeopterodactyloids, this new specimen shares with Forfexopterus the specific wing phalanx proportions with the first wing phalanx shorter than the second phalanx and longer than the third phalanx (Jiang et al., 2016), previously considered an autapomorphy of the genus Forfexopterus. The proportions of other wing elements of the new specimen are also comparable with those of Forfexopterus (Table 1), whereas they clearly differ from those of the other Jehol Biota pterosaurs. In addition, the new specimen is also from the same horizon and area as the holotype of Forfexopterus (HM V20). Based on all these aspects we consider the new specimen SDUST-V1003 to belong to Forfexopterus as well.

As aforementioned, SDUST-V1003 represents a mature individual, evident by the fused scapulocoracoid and the syncarpals, the extensor tendon process fused with the first wing phalanx, and the well-ossified humerus. Based on Bennett's $(1993,2018)$ size-independent criteria in the pterosaur ontogeny, these features indicate that SDUST-V1003 is at the highest stage of the maturity (adult). In contrast, the type specimen (HM V20) is immature (subadult) and lacks all of these ossified features, except for the ossified syncarpals. Therefore, the two specimens could be well separated in ontogenetic stages. Interestingly, SDUST-V1003 has a wing span of about $75 \%$ of that of HM V20, even if SDUSTV1003 is ontogenetically more developed than HM V20. This discrepancy reveals developmental variation of Forfexopterus.

The developmental variation showed as a counterintuitive size variation is also known in other pterosaurs (e.g., Pteranodon, Rhamphorhynchus; Bennett, 1993; Prondvai et al., 2012). However, in some cases (e.g., Pteranodon, Hamipterus), the size difference is possibly caused by the sexual dimorphism: the female appears to be smaller than the male (e.g., Bennett, 1992; Wang et al., 2014). For example, in Pteranodon, the mature female is about two-thirds the 
size of the mature male (Bennett, 1992, 1993). The sexual dimorphism of some pterosaurs is identifiable from the cranial crest (e.g., Pteranodon, Darwinopterus, Hamipterus). The cranial crest is more developed in males than in females (e.g., Pteranodon, Hamipterus) (e.g., Bennett, 1992, 2001; Wang et al., 2014), or even absent in the female (Darwinopterus; Lü et al., 2011). Apart from sexual dimorphism, developmental variation is evident by the wide range of the size of adult specimens (the smallest individual about $70 \%$ the size of the largest individual) in each sex of Pteranodon (Bennett, 1993). A similar condition is also confirmed in Rhamphorhynchus by osteological and paleohistological information (Bennett, 1995; Prondvai et al., 2012).

In the Jehol Biota, the ctenochasmatids flourished with a high diversity but lack evidence of sexual dimorphism. A size variation has been reported in Elanodactylus between two adult specimens. A small skeleton is about $70 \%$ of the type specimen in wing span (Andres and Ji, 2008; Zhou, 2010). Unfortunately, the cranial morphology is unknown in both specimens. The connection between the size variation and the sexual dimorphism is uncertain in Elanodactylus. In Forfexopterus, as mentioned by Jiang et al. (2016), HM V20 would have been larger if it reached its skeletal maturity. The size variation of Forfexopterus would be comparable with that of Elanodactylus, which also implies a similar developmental variation. Although sexual dimorphism needs to be further investigated with more fossil materials, this discovery sheds new light on understanding the paleobiology of the ctenochasmatids in the Jehol Biota.

Data availability. The specimen of Forfexopterus describe in this study is stored in Vertebrate Paleontological Collection of College of Earth Science and Engineering, Shandong University of Science and Technology, Qingdao City, Shandong Province, China (accession number: SDUST-V1003).

Author contributions. CFZ conceived the project. CFZ and ZZ created figures, CFZ wrote the paper, and all of authors approved the paper.

Competing interests. The authors declare that they have no conflict of interest.

Acknowledgements. The authors would like to thank S. Christopher Bennett and one anonymous reviewer for their helpful comments on the manuscript. Thanks are owed to David M. Unwin for his comments that improved the quality of this paper. Qiang Yang is thanked for his skillful preparation of the specimen.

Financial support. This research has been supported by the Taishan Scholar Program of Shandong Province (grant no. tsqn201812070), the Shandong Provincial Natural Science Foundation (grant no. ZR2017MD031), the Program for Innovative Research Team of Excellent Talents in University of Shandong Province (grant no. 2019KJH004), and the Research Fund of Shandong University of Science and Technology (grant no. 2015TDJH101).

Review statement. This paper was edited by Torsten Scheyer and reviewed by Christopher Bennett and one anonymous referee.

\section{References}

Andres, B. and Ji, Q.: A new pterosaur from the Liaoning Province of China, the phylogeny of the Pterodactyloidea, and convergence in their cervical vertebrae, Palaeontology, 51, 453-469, 2008.

Andres, B., Clark, J., and Xu, X.: The earliest pterodactyloid and the origin of the group, Curr. Biol., 24, 1011-1016, 2014.

Bennett, S. C.: Sexual dimorphism of Pteranodon and other pterosaurs, with comments on cranial crests, J. Vertebr. Paleontol., 12, 422-434, 1992.

Bennett, S. C.: The ontogeny of Pteranodon and other pterosaurs, Paleobiology, 19, 92-106, 1993.

Bennett, S. C.: A statistical study of Rhamphorhynchus from the Solnhofen Limestone of Germany: year-classes of a single large species, J. Paleontol., 69, 569-580, 1995.

Bennett, S. C.: The osteology and functional morphology of the Late Cretaceous pterosaur Pteranodon, Palaeontogr. Abt. A, 260, 1-153, 2001.

Bennett, S. C.: New smallest specimen of the pterosaur Pteranodon and ontogenetic niches in pterosaurs, J. Paleontol., 92, 254-271, https://doi.org/10.1017/jpa.2017.84, 2018.

Chang, S.-C., Zhang, H., Renne, P. R., and Fang, Y.: High-precision ${ }^{40} \mathrm{Ar} /{ }^{39} \mathrm{Ar}$ age for the Jehol Biota, Palaeogeogr. Palaeocl., 280, 94-104, 2009.

Chang, S.-C., Gao, K.-Q., Zhou, C.-F., and Jourdan, F.: New chronostratigraphic constraints on the Yixian formation with implications for the Jehol Biota, Palaeogeogr. Palaeocl., 487, 399406, https://doi.org/10.1016/j.palaeo.2017.09.026, 2017.

Jiang, S., Cheng, X., Ma, Y., and Wang, X.: A new archaeopterodactyloid pterosaur from the Jiufotang Formation of western Liaoning, China, with a comparison of sterna in Pterodactylomorpha, J. Vertebr. Paleontol., 36, e1212058, https://doi.org/10.1080/02724634.2016.1212058, 2016.

Kellner, A. W. A.: Pterosaur phylogeny and comments on the evolutionary history of the group, in: Evolution and Palaeobiology of Pterosaurs, edited by: Buffetaut, E. and Mazin, J.-M., Geol. Soc. London, Special Publications, 217, 105-137, 2003.

Liu, D.-X., Zhou, C.-F., Wang, J.-Q., Li, W.-G., and Wei, Q.-W.: New data on the cervical morphology of the Chinese tapejarine, Hist. Biol., 27, 638-645, https://doi.org/10.1080/08912963.2014.885962, 2015.

Lü, J.-C.: A new pterosaur: Beipiaopterus chenianus, gen. et sp. nov. (Reptilia: Pterosauria) from western Liaoning Province of China, Memoir of the Fukui Prefectural Dinosaur Museum, 2, 153-160, 2003. 
Lü, J., Gao, C., Meng, Q., Liu, J., and Ji, Q.: On the systematic position of Eosipterus yangi Ji et Ji, 1997 among pterodactyloids, Acta Geol. Sin.-Engl., 80, 643-646, 2006.

Lü, J., Unwin, D. M., Deeming, D. C., Jin, X., Liu, Y., and Ji, Q.: An egg-adult association, gender, and reproduction in pterosaurs, Science, 331, 321-324, 2011.

Lü, J., Pu, H., Xu, L., Wu, Y., and Wei, X.: Largest toothed pterosaur skull from the Early Cretaceous Yixian Formation of Western Liaoning, China, with comments on the family Boreopteridae, Acta Geol. Sin.-Engl., 86, 287-293, 2012.

Lü, J., Kundrát, M., and Shen, C.: New material of the pterosaur Gladocephaloideus Lü et al., 2012 from the Early Cretaceous of Liaoning Province, China, with comments on its systematic position, PLoS ONE, 11, e0154888, https://doi.org/10.1371/journal.pone.0154888, 2016.

Pan, Y.-Q., Gao, F.-L., Zhang, G.-R., Wang, X., and Wu, Z.-J.: New discovery of phytolith from Jiufotang Formation in Xiaotaizi Area, Liaoning Province, Geol. Resources, 24, 87-92, 2015 (in Chinese with English Abstract).

Prondvai, E., Stein, K., Osi, A., and Sander, M. P.: Life history of Rhamphorhynchus inferred from bone histology and the diversity of pterosaurian growth strategies, PLoS ONE 7, e31392, https://doi.org/10.1371/journal.pone.0031392, 2012.

Unwin, D. M.: On the phylogeny and evolutionary history of pterosaurs, in: Evolution and Palaeobiology of Pterosaurs, edited by: Buffetaut, E. and Mazin, J.-M., Geol. Soc. London, Special Publications, 217, 139-190, 2003.
Wang, X., Kellner, A. W. A., Zhou, Z., and Campos, D. A.: Pterosaur diversity and faunal turnover in Cretaceous terrestrial ecosystems in China, Nature, 437, 875-879, 2005.

Wang, X., Kellner, A. W. A., Zhou, Z., and Campos, D. A.: A new pterosaur (Ctenochasmatidae, Archaeopterodactyloidea) from the Lower Cretaceous Yixian Formation of China, Cretaceous Res., 28, 245-260, 2007.

Wang, X., Kellner, A. W. A, Jiang, S., Wang, Q., Ma, Y., Paidoula, Y., Cheng, X., Rodrigues, T., Meng, X., Zhang, J., Li, N., and Zhou, Z.: Sexually dimorphic tridimensionally preserved pterosaurs and their eggs from China, Curr. Biol., 24, 1323-1330, 2014.

Wu, Z., Gao, F., Pan, Y., and Wang, X.: Division and correlation of the Jiufotang Formation and their rare fossil-bearing beds in western Liaoning, China, Geoscience, 32, 758-765, 2018 (in Chinese with English Abstract).

Zhou, C.-F.: New material of Elanodactylus prolatus Andres \& Ji, 2008 (Pterosauria: Pterodactyloidea) from the Early Cretaceous Yixian Formation of western Liaoning, China, Neues Jahrb. Geol. P.-A., 255, 277-286, 2010.

Zhou, C.-F., Gao, K.-Q., Yi, H., Xue, J., Li, Q., and Fox, R. C.: Earliest filter-feeding pterosaur from the Jurassic of China and ecological evolution of Pterodactyloidea, Roy. Soc. Open Sci., 4, 160672, https://doi.org/10.1098/rsos.160672, 2017. 